\title{
Seasonal variation of the ion upflow in the topside ionosphere during SAPS (subauroral polarization stream) periods
}

\author{
H. Wang ${ }^{1}$ and H. Lühr ${ }^{2}$ \\ ${ }^{1}$ Dept. of Space Physics, School of Electronic Information, Wuhan University, Wuhan 430072, China \\ ${ }^{2}$ Helmholtz Centre Potsdam - GFZ, German Research Center for Geosciences, 14473 Potsdam, Germany \\ Correspondence to: H. Wang (h.wang@whu.edu.cn)
}

Received: 29 November 2012 - Revised: 22 July 2013 - Accepted: 24 July 2013 - Published: 6 September 2013

\begin{abstract}
A statistical study has been performed by using two years of DMSP (Defense Meteorological Satellite Program) plasma observations to investigate the seasonal effect of SAPS (subauroral polarization stream) on the ion upflow in the duskside ionosphere of the Northern Hemisphere. There are obvious upflows occurring in the topside ionosphere around the SAPS region, exceeding $200 \mathrm{~m} \mathrm{~s}^{-1}$ at winter solstice, indicating an important relationship between SAPS and the local plasma upward motion. Both SAPS and ion upward velocities show similar seasonal variations, largest in winter and smallest in summer, irrespective of geomagnetic activity. A good correlation is found and a linear relationship is derived between SAPS and the ion upflow velocities. During December solstice the average upflow flux can reach about $2 \times 10^{8} \mathrm{~cm}^{-2} \mathrm{~s}^{-1}$ for more disturbed periods, which is comparable to the typical upflow flux in the dayside cusp region. The depression of the ion temperatures around the peak SAPS region can be understood in terms of the adiabatic cooling. The hot ion cools down when expanding into the low ion concentration region. The electron temperature elevates around the SAPS region because of the reduced Coulomb cooling in the low ion density region. Both the changes of ion and electron temperatures are larger in winter than in summer, however, for $\mathrm{Kp}<4$ the electron temperatures are almost seasonably independent. The present work highlights the important role of the SAPS-related frictional heating at mid-latitudes on the local formation of the strong upward flow, which might provide a direct ionospheric ion source for the ring current and plasmasphere in the duskside sector.
\end{abstract}

Keywords. Ionosphere (mid-latitude ionosphere; plasma convection; plasma temperature and density)

\section{Introduction}

The ionospheric upflow plays an important role in the magnetosphere-ionosphere coupling process, providing the ionospheric $\mathrm{O}^{+}$for the magnetosphere (Shelley et al., 1972). Previous works have investigated the upflow characteristics and mechanisms by using spacecraft and radar observations combined with model simulation (Yau et al., 1984; Heelis et al., 1984; Lockwood et al., 1985; Loranc et al., 1991; Rodger et al., 1992; Wu et al., 1992; Foster and Lester, 1996; Yau and Andre, 1997; Horwitz and Moore, 1997; Su et al., 1999; Malingre et al., 2000; Liu et al., 2001; Coley et al., 2006; Coley and Heelis, 2009). The ion upflow prefers to occur in the cusp and auroral region (Yau et al., 1984; Loranc et al., 1991; Wu et al., 1992) and at the auroral oval poleward boundary (Lockwood et al., 1985; Malingre et al., 2000). The occurrence frequency of the auroral upflow shows a dawn-dusk asymmetry, more frequent in the dusk sector (Liu et al., 2001). Upflows are observed at altitudes ranging from $200 \mathrm{~km}$ to several thousand kilometers, and the probability of occurrence increases with the altitude and solar and geomagnetic activity, e.g. Kp, solar flux, and solar wind dynamic pressure (Ghielmetti et al., 1978; Yau et al., 1984; Lockwood et al., 1985; Pollock et al., 1990; Moore et al., 1999; Liu et al., 2001; Elliott et al., 2001; Cully et al., 2003; Lennartsson et al., 2004). The occurrence frequency exhibits seasonal variation, which is altitude dependent. At higher altitudes (above $8000 \mathrm{~km}$ ) the occurrence is in favor of the summer season (Yau et al., 1984), while at $\mathrm{F}$ region the occurrence prefers winter (e.g. Liu et al., 2001; Coley et al., 2006). 
The acceleration mechanisms of the ion upflow include parallel electric field, magnetic momentum pumping, waveparticle interaction, auroral plasma cavity, etc., which are generally effective above $1000 \mathrm{~km}$ (Sharp et al., 1977; Papadopoulos, 1977; Whalen et al., 1978; Retterer et al., 1986; Singh et al., 1989; Yau and Andre, 1997; Moore et al., 1999). At $\mathrm{F}$ heights the mechanisms include frictional heating and particle precipitation (Moffett et al., 1991; Rodger et al., 1992; Wahlund et al., 1992; Wilson, 1994; Liu et al., 1995; Coley et al., 2006). Moffett et al. (1991) have found that $\mathrm{O}^{+}$upflow together with $\mathrm{H}^{+}$and $\mathrm{He}^{+}$in the topside ionosphere results predominately from frictional heating. Kervalishvili and Lühr (2013) have associated the cusp upflow to the enhanced electron temperature due to intense electron precipitation. Rodger et al. (1992) have reviewed the possible generation mechanisms for the high-latitude ionospheric ion upflow. Wilson (1994) has shown that the upflow becomes faster when the neutral atmosphere is cooler and when the large convection electric field is turned on more quickly. There are two types of ion upflow in the auroral zone (Wahlund et al., 1992). Type 1 is related to the enhanced perpendicular ion temperature due to frictional heating. Type 2 is associated with the enhanced electron temperature due to electron precipitation, which can induce field-aligned electric fields forcing the ions to move upward. Usually Type 2 is more frequent and stronger than Type 1 as stated by Wahlund et al. (1992). There are other cases where the upflow in the auroral region is accompanied by both elevated ion and electron temperature (e.g. Foster and Lester, 1996; Förster et al., 1999).

Although a lot of studies have concentrated on ion upflow at high latitudes, an interesting and important feature at midlatitude, the effect of subauroral polarization stream (SAPS) on ion upflow, has not been investigated statistically. The term SAPS was introduced by Foster and Burke (2002) to refer to the rapid westward plasma flow located equatorward of the auroral oval, predominantly in the dusk and pre-midnight sector (16:00 to 24:00 magnetic local time, MLT). The term tends to encompass two distinct phenomena. One is the polarization jets (PJs) (Galperin et al., 1974) or subauroral ion drifts (SAIDs) (Spiro et al., 1979), featured as more intense $\left(\sim 1000 \mathrm{~m} \mathrm{~s}^{-1}\right)$ and latitudinally narrower plasma flow. The other exhibits a wider latitudinal extent and longer duration of plasma flow, as described by Yeh et al. (1991). In the present study we are referring to both types of flows. Since the location of SAPS is conjugate to the peak ring current energy density (Yeh et al., 1991; Foster and Vo, 2002), and coincides with the equatorward edge of the ion plasma sheet (Southwood and Wolf, 1978; Anderson et al., 1993; Huang and Foster, 2007), the upward ions in the SAPS region might contribute to the development of the storm time ring current. From this aspect a statistical study of SAPS effects on ion upflow might aid understanding the ionosphere-inner magnetosphere coupling.
Some case studies of ion upflow associated with SAPS from models and observations have been presented previously. Yeh and Foster (1990) have reported about a large ion upflow event exhibiting a velocity of $3 \mathrm{~km} \mathrm{~s}^{-1}$ at $1000 \mathrm{~km}$ altitude around the SAPS region observed by Millstone Hill during the February 1986 storm. Another strong upward ion flux of $5 \times 10^{9} \mathrm{~cm}^{-2} \mathrm{~s}^{-1}$ around a SAPS region has also been observed by Millstone Hill during the November 2004 storm (Erickson et al., 2010). Anderson et al. (1991) have reported a large $\mathrm{O}^{+}$upflow of $900 \mathrm{~m} \mathrm{~s}^{-1}$ collocated with a SAPS of $1000 \mathrm{~m} \mathrm{~s}^{-1}$ plasma drift at $400 \mathrm{~km}$ altitude. However, some model studies have shown that large horizonal flow velocities at subauroral regions can induce upward flow only in the topside ionosphere but downward flow around $400 \mathrm{~km}$ (Sellek et al., 1991; Korosmezey et al., 1992). Moffett et al. (1992) have simulated the response of the topside ionosphere to the sudden onset of a SAPS exceeding $1 \mathrm{~km} \mathrm{~s}^{-1}$. They have found that the enhanced ion upflow subsides after a new equilibrium scale height is attained. Heelis et al. (1993) have shown that with quicker raise time of a SAPS the upflow velocity will get larger. However, there are only a few papers on the seasonal and geomagnetic activity dependence of SAPS effects on the ion upflow in the topside ionosphere.

In this paper we show statistical results of the vertical upflow (i.e. drift speed and ion/electron temperature) related to SAPS in the northern subauroral topside ionosphere $(\sim$ $800 \mathrm{~km}$ ) by using two years of DMSP (Defense Meteorological Satellite Program) observations during 2002 and 2003. Of particular interest are the seasonal and geomagnetic activity dependences. In the following section we briefly describe the method of data processing. Section 3 describes the statistical results. In the discussion section we compare results with previous reports and offer explanations.

\section{DMSP IDM and SSJ/4 data}

The DMSP spacecrafts have an orbital period of roughly $100 \mathrm{~min}$ and fly around the Earth about 14 times per day at an altitude of about $800 \mathrm{~km}$. The DMSP F13 monitors the topside ionosphere in the dawn-dusk plane. Of particular interest are the ion drift velocities measured by the ion drift meter (IDM) in both horizontal and vertical directions perpendicular to the satellite orbit (Rich and Hairston, 1994). In this work the cross-track velocity has been used to identify the SAPS event and the vertical velocity to describe the ion upflow. The total ion density comes from the scintillation meter. At $800 \mathrm{~km}$ altitude, $\mathrm{O}^{+}$is the dominant ion species during the years considered here (e.g. Coley et al., 2006). The retarding potential analyzer measures the average ion temperature, and the Langmuir probe measures the electron temperature. Only high-quality Flag 1 data are used in the study.

The DMSP electron spectrometer (SSJ/4) instruments provide the average energy flux of electron and ion in the energy range of $30 \mathrm{eV}$ to $30 \mathrm{keV}$ (Hardy et al., 1984), from which 

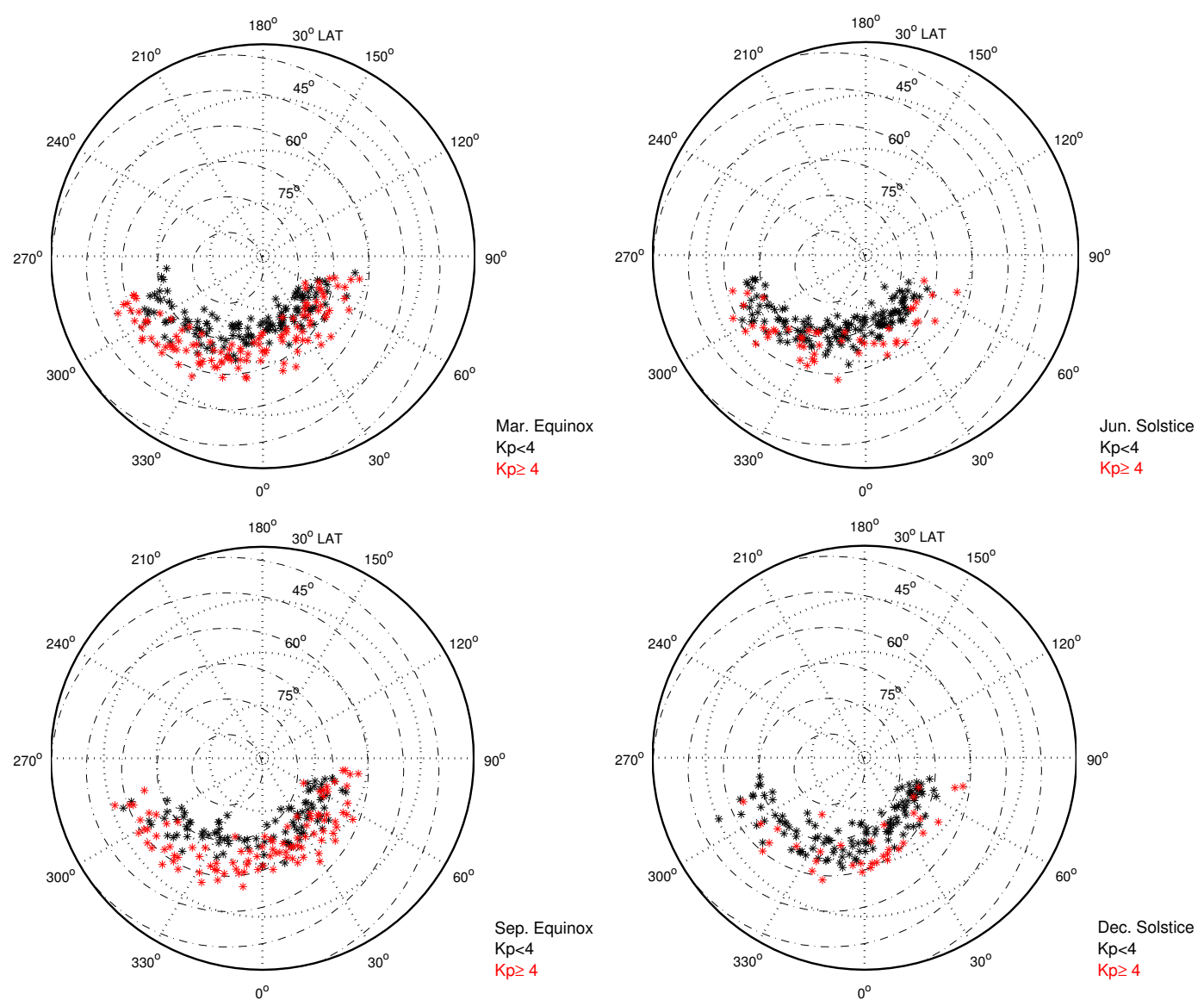

Fig. 1. Locations of DMSP F13 SAPS detections in the geographical latitude and longitude in the Northern Hemisphere for each season and $\mathrm{Kp}$ bin. Geomagnetic latitude contours are also shown as dotted-dashed lines at $10^{\circ}$ separately.

Table 1. The number of selected DMSP SAPS events and mean Kp value in each season group. The abbreviation "ME" denotes March equinox, "JS” June solstice, “SE” September equinox, "DS” December solstice.

\begin{tabular}{cccccc}
\hline \multirow{2}{*}{ Season } & \multicolumn{2}{c}{ Kp $<4$} & & \multicolumn{2}{c}{ Kp $\geq 4$} \\
\cline { 2 - 3 } \cline { 5 - 6 } \cline { 5 - 6 } & Number of events & Mean Kp & & Number of events & Mean Kp \\
\hline ME & 133 & 2.6 & & 117 & 4.9 \\
JS & 149 & 2.6 & & 49 & 4.8 \\
SE & 96 & 2.7 & & 101 & 4.9 \\
DS & 118 & 2.7 & & 34 & 4.4 \\
\hline
\end{tabular}

the height-integrated ionospheric conductivity can be derived (Robinson et al., 1987). The subauroral region is found automatically by computing the auroral Pedersen conductance along the DMSP path and determining the peak conductance, then stepping equatorward until the conductance is reduced to 0.2 times the peak value or to $1^{\circ} \mathrm{S}$, whichever is smaller. SAPS are defined as rapid sunward (westward) plasma flows greater than $100 \mathrm{~m} \mathrm{~s}^{-1}$ in the subauroral and premidnight region. The selected orbits are further visually inspected to fully satisfy the above criteria. The detailed description of our approach for identifying SAPS can be found in Wang et al. (2008). DMSP passes which have angles between the orbit track and the auroral oval of less than $45^{\circ}$ have been discarded to guarantee that the DMSP cross-track direction is approximately aligned with the auroral oval.

The number of SAPS events for each season and for less disturbed $(\mathrm{Kp}<4)$ and disturbed $(\mathrm{Kp} \geq 4)$ geomagnetic conditions are listed in Table 1. Overall, we have of the order of 30 or more events in each bin, which can be regarded as sufficient for a statical study. When normalized by the total numbers of F13 passes obeying to the same conditions, e.g. Kp, season, and $45^{\circ}$ angle criteria, the probability of observing a 


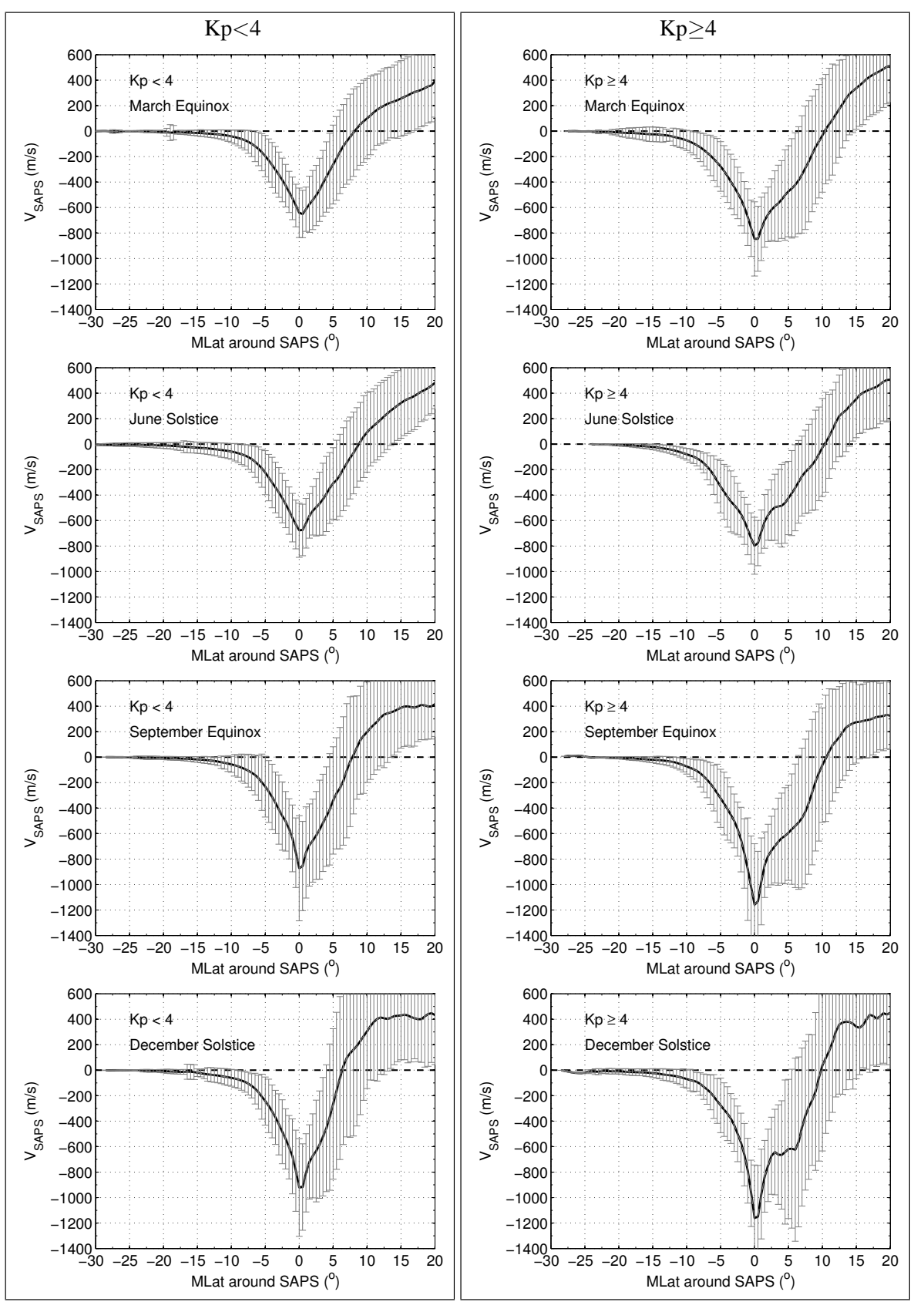

Fig. 2. Superposed epoch analysis of the cross-track velocity observed by DMSP F13 for different seasons and Kp levels. From top to bottom results are shown for local seasons of spring, summer, autumn and winter. The key MLat of "0" denotes the latitude where the SAPS velocity peak occurs. Positive values denote eastward velocity. The bars show the standard deviations of $0.5^{\circ}$ averages.

SAPS event is $14 \%(41 \%), 11 \%(28 \%), 15 \%(20 \%)$, and $11 \%(28 \%)$ in spring, autumn, summer and winter during $\mathrm{Kp}<4(\mathrm{Kp} \geq 4)$, respectively. The mean $\mathrm{Kp}$ index for each of the seasons is also listed in Table 1, which is quite constant over the year. Thus, there is no activity bias in the seasonal results.

The locations of observed SAPS are plotted on geographic coordinates, as shown in Fig. 1. Local spring, summer, au- tumn and winter are shown individually. Each season covers three months, where June solstice covers June to August and December solstice covers December, January, and February. The remaining 6 months are related to March and September equinoxes. It can be seen that SAPS events are located in the American-European sector within the range $280^{\circ} \mathrm{E}$ to $80^{\circ} \mathrm{E}$ of longitude. This does not reflect the actual distribution of SAPS, but the confinement of events in longitude is caused 

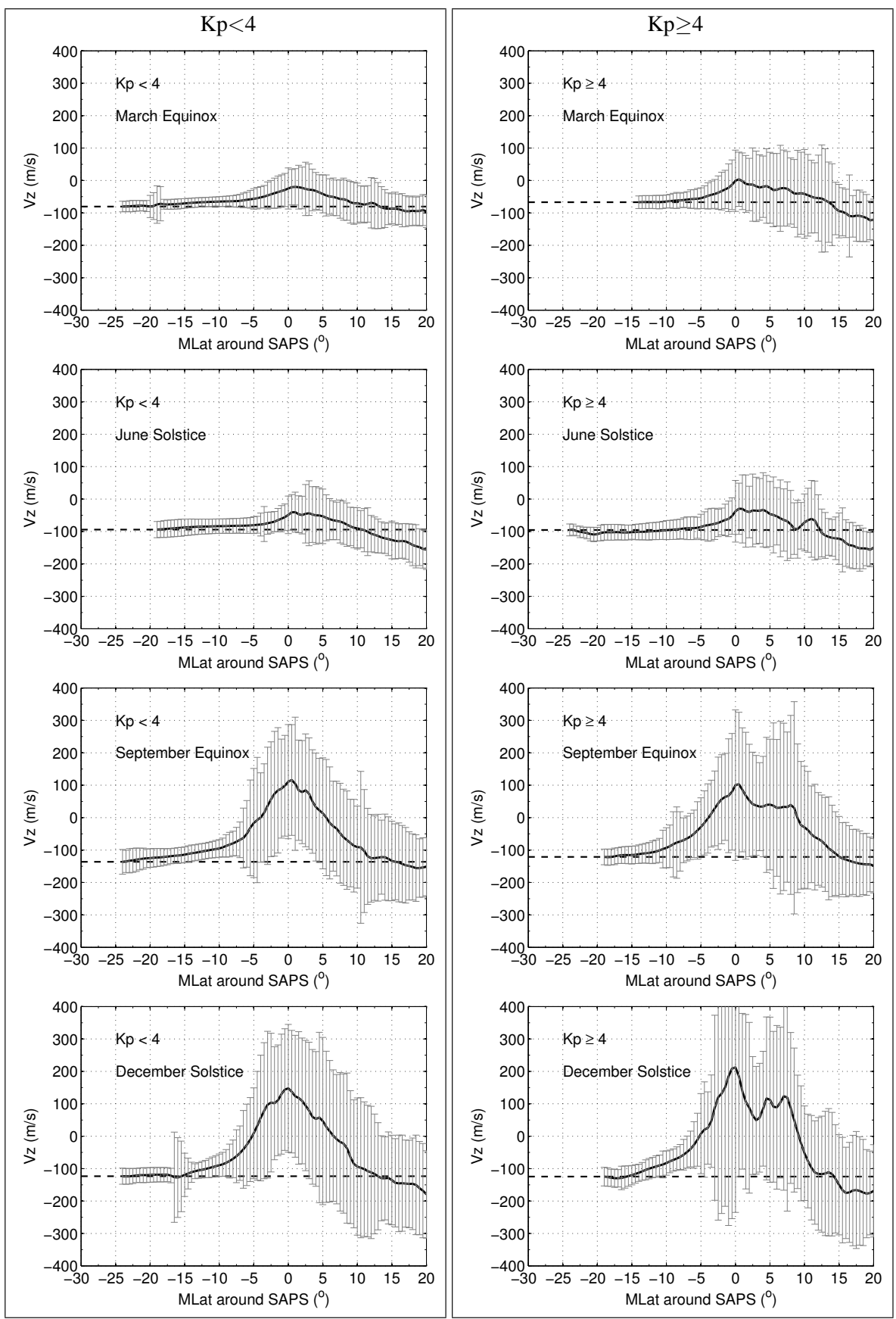

Fig. 3. The same as Fig. 2 but for the vertical flow velocity. Positive values denote upward flow velocity. The background velocity is indicated by a dashed line.

by our selection criteria (angle between orbit track and auroral oval larger than $45^{\circ}$ and Flag $=1$ ) which suppress all other observations.

\section{Statistical results}

In order to find out the latitudinal relation between SAPS and the upflow appearance, we have performed a superposed epoch analysis (SEA) for both SAPS and ion upflow. We take the location of SAPS peak velocity as the key latitude, around which the latitude profile of DMSP data are stacked. The mean velocity profiles are obtained with $0.5^{\circ}$ MLat (magnetic latitude) resolution. We consider the variations over a latitude range from $30^{\circ}$ equatorward of the SAPS velocity peak to $20^{\circ}$ poleward of the SAPS peak. The potential offsets at low latitudes have been removed by using the same 



Fig. 4. The same as Fig. 2 but for electron density. The background level is indicated by a dashed line.

method as Hairston et al. (1998) before averaging. We have established a linear baseline for the polar pass by using velocity data around $40^{\circ}$ MLat. When the linear baseline (residual velocity) is removed, the velocity at the endpoints (around $40^{\circ}$ MLat) can reach zero.

Figure 2 shows the average distribution of cross-track plasma velocities observed by DMSP for moderate $(\mathrm{Kp}<4)$ and enhanced geomagnetic activity $(\mathrm{Kp} \geq 4)$. From top to bottom local seasons are spring, summer, autumn and winter, respectively. In Fig. 2 peak westward flows occur as ex- pected at zero latitude, which are the SAPS. With more increasing geomagnetic activity SAPS become larger in magnitude. SAPS peak velocities in winter are larger than in summer, irrespective of the geomagnetic activity level. The standard variation is not small in Fig. 2, which indicates the large variability of the SAPS velocity at a certain magnetic activity level. Previous work has also shown a large scatter in the SAPS velocity at constant magnetic activity (e.g. Wang et al., 2008). 

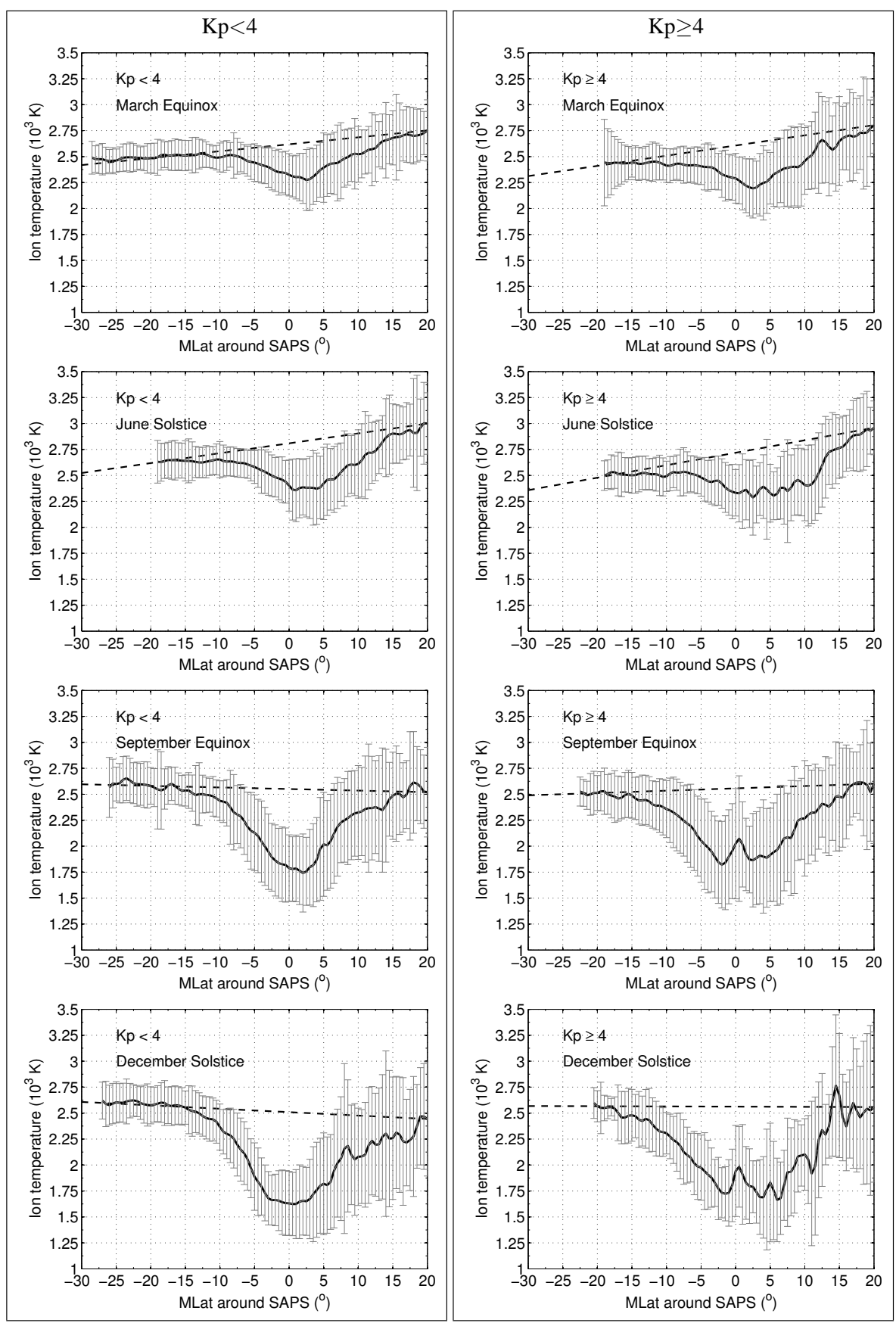

Fig. 5. The same as Fig. 2, but for ion temperature. The background trend is indicated by a dashed line.

The average latitudinal variation of the ion upflow is presented in Fig. 3 in the same format as Fig. 2. The horizontal dashed line indicates the background trend of the vertical flow, which is downward with a value of $100 \mathrm{~m} \mathrm{~s}^{-1}$, indicating a general downward flux at the equatorward and poleward sides of the auroral region (i.e. at low latitude and polar cap). There is a clear pattern of upward plasma flow occurring around the SAPS peak, indicative of the significant effect of the SAPS westward plasma drift on the ion upflow. The peak value of ion upflow velocity is near zero in spring and summer, but is more than $100 \mathrm{~m} \mathrm{~s}^{-1}$ in autumn and $200 \mathrm{~m} \mathrm{~s}^{-1}$ in winter. When looking at the variation of the vertical flow after subtraction of the background trend, we find about $100 \mathrm{~m} \mathrm{~s}^{-1}$ in the upward direction to occur in spring and summer, and approximately $200-300 \mathrm{~m} \mathrm{~s}^{-1}$ in autumn and winter. Both the flow velocity and variation get stronger with increasing geomagnetic activity. 

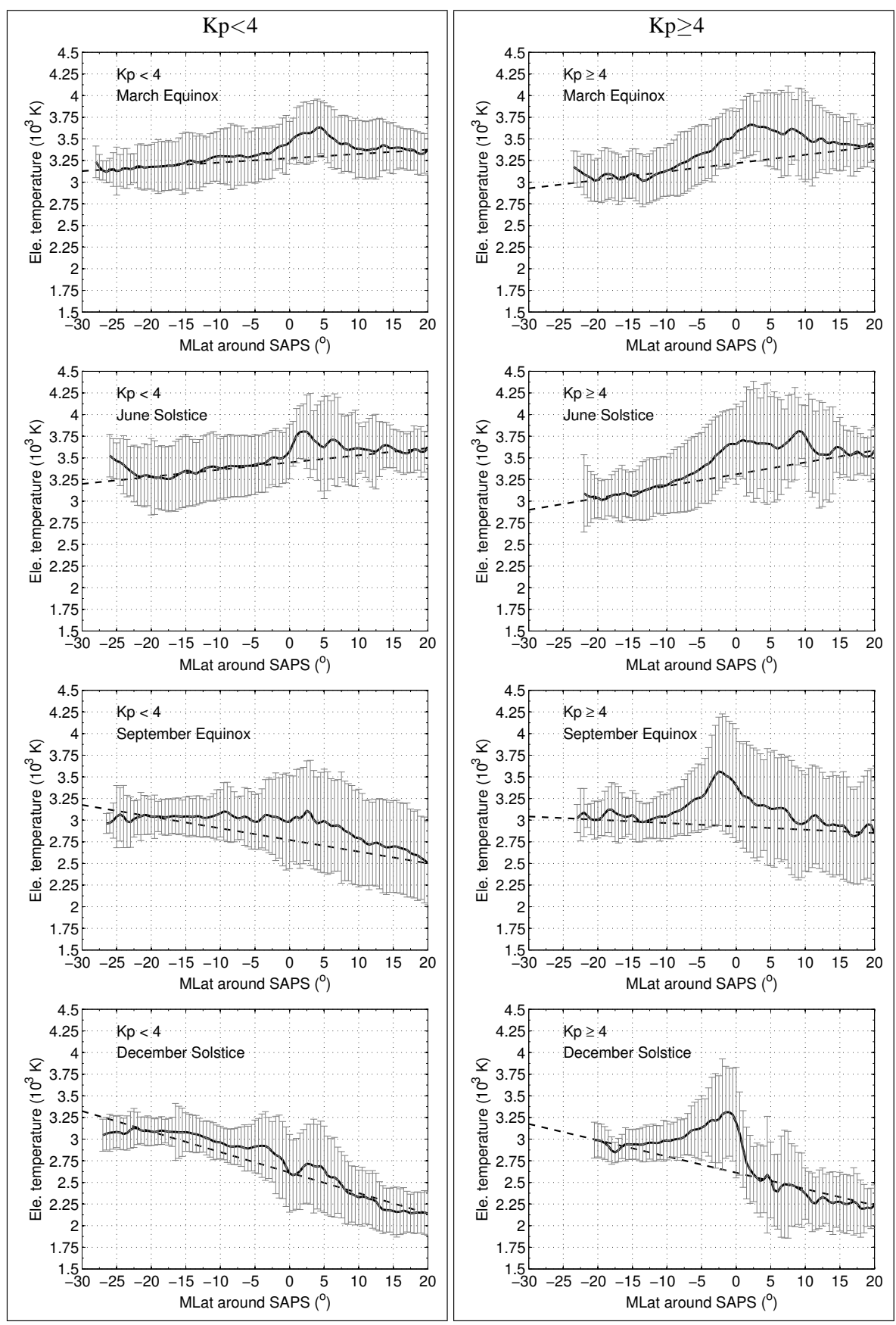

Fig. 6. The same as Fig. 2 but for electron temperature. The background trend is indicated by a dashed line.

The ion density is presented in Fig. 4. There is a dropout of electron (ion) density around the key latitude, which represents the mid-latitude trough. The trough density reduces when the geomagnetic activity increases and exhibits a clear seasonal variation due to solar illumination, with larger densities in summer than in winter.

The ion and electron temperature at $800 \mathrm{~km}$ altitude are illustrated in Figs. 5 and 6. Interestingly, it can be noticed that the ion temperature drops down while the electron tempera- ture enhances around the peak SAPS region. The changes are larger in winter than in summer.

\section{Discussion}

We have presented the seasonal variations of SAPS and ion upflow around subauroral latitudes by using DMSP observations in the top ionosphere. SAPS have a remarkable effect 


\section{SAPS velocity}

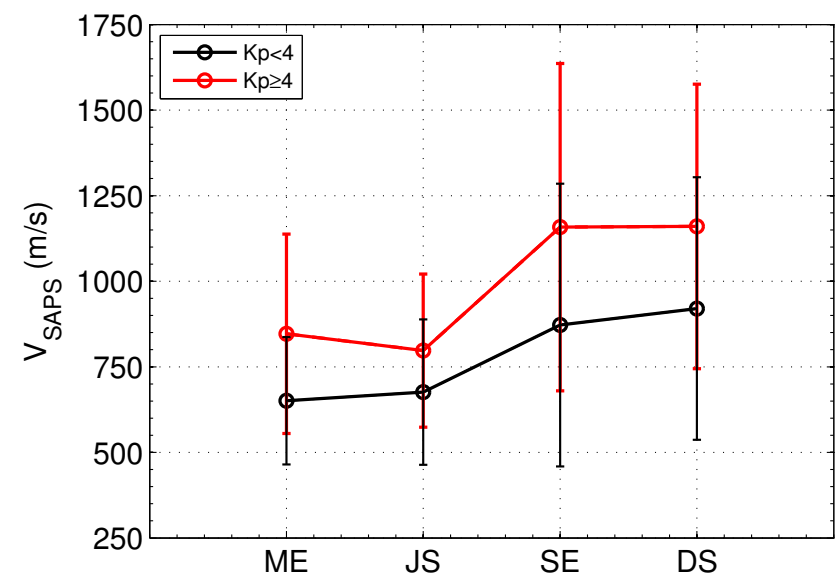

Upflow velocity

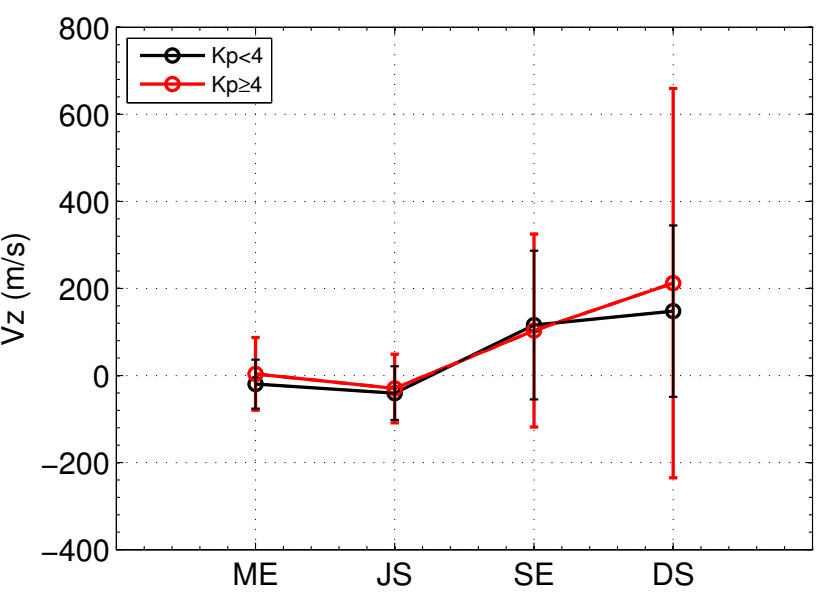

Fig. 7. Seasonal variation of the SAPS velocity (left) and upflow velocity (right) at the key MLat at $800 \mathrm{~km}$ altitude for Kp $<4$ and Kp $\geq 4$. The bars show the standard deviations of averages.

on the ion upflow in a statistical sense. Both peak in the same region. Our work has shown that SAPS of around $1.2 \mathrm{~km} \mathrm{~s}^{-1}$ can yield on average an upflow velocity of $\sim 200 \mathrm{~m} \mathrm{~s}^{-1}$ in winter, which is within the range of previous reports. Previous case studies have reported that the upward velocity increases with altitude, and the typical velocity at the altitude of $1000 \mathrm{~km}$ or less is around a few hundred $\mathrm{ms}^{-1}$ (Wilson, 1994). Foster and Lester (1996) have reported an upward ion velocity of $300 \mathrm{~m} \mathrm{~s}^{-1}$ at $800 \mathrm{~km}$ altitude in the auroral zone, which is related to the ion heating caused by the enhanced and sheared convection velocity at $F$ region altitudes. Wahlund et al. (1992) have observed a $100 \mathrm{~m} \mathrm{~s}^{-1}$ upward flow below $500 \mathrm{~km}$ in the auroral zone. Anderson et al. (1991) have observed a higher upward velocity around $900 \mathrm{~m} \mathrm{~s}^{-1}$ at $400 \mathrm{~km}$ altitude. Korosmezey et al. (1992) have modeled the effect of SAPS of $3 \mathrm{~km} \mathrm{~s}^{-1}$ and yielded an upward flow velocity of $100 \mathrm{~m} \mathrm{~s}^{-1}$ near $900 \mathrm{~km}$, and when the SAPS velocity increases to $4 \mathrm{~km} \mathrm{~s}^{-1}$, the maximum upflow velocity reaches $400 \mathrm{~m} \mathrm{~s}^{-1}$. The model work by Wilson (1994) has shown that the peak upward flow below $1000 \mathrm{~km}$ altitude is only $0.9 \mathrm{~km} \mathrm{~s}^{-1}$ when the auroral convection velocity is $2 \mathrm{~km} \mathrm{~s}^{-1}$. However, some model work has shown that above $500 \mathrm{~km}$ altitude the upward flow can reach as high as $1.9 \mathrm{~km} \mathrm{~s}^{-1}$ when the auroral convection velocity is $2 \mathrm{~km} \mathrm{~s}^{-1}$ (e.g. Sellek et al., 1991; Heelis et al., 1993). The model differences can be explained by the following conditions: whether there is an ion temperature anisotropy or not, a slower or quicker ramp-up time in turning on the convection velocity, or a uniform or non-uniform altitude profile of the electron temperature (e.g. Wilson, 1994).

\subsection{Zonal and upflow velocities}

The seasonal variation of the peak velocity of both horizontal and vertical plasma flows are shown in Fig. 7 for two differ-

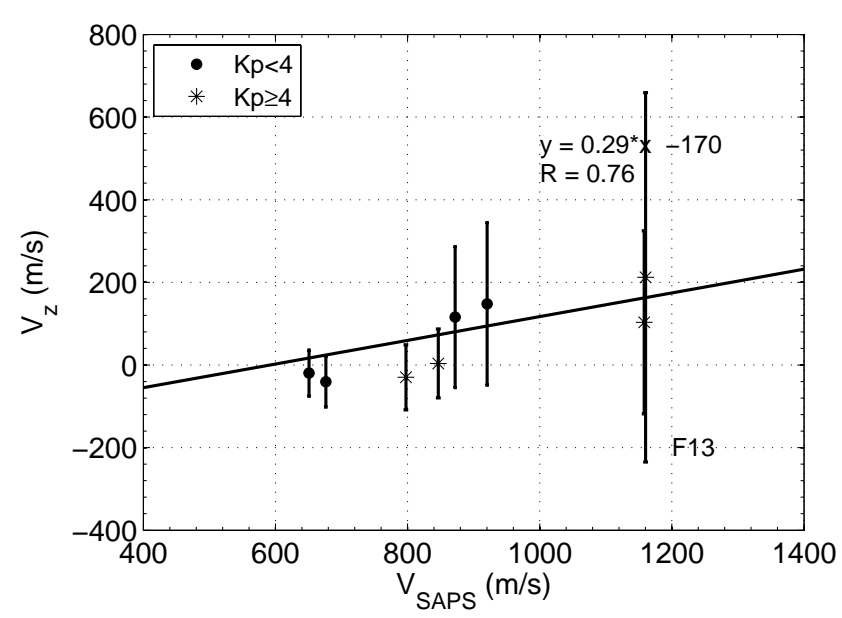

Fig. 8. Correlation of SAPS with the upflow velocity in the Northern Hemisphere. The correlation coefficient, $R$, the regression line and the fitting function are also shown in the frame. The bars show the standard deviations of averages.

ent geomagnetic activities. The error bars have been shown in Fig. 7. The variability is substantial, but the general character of the curves is conserved. In the top frame SAPS peaks are shown. SAPS are more rapid in winter than in summer, in line with the fact that the SAPS velocity is inversely proportional to the ionospheric conductivity primarily caused by the solar illumination in the subauroral region, which is larger in summer than in winter (Anderson et al., 2001). The smaller conductivity requires an increase in the polarization electric field (and SAPS velocity) in order to maintain the current continuity in the subauroral region. In the bottom frame of Fig. 7 the peak values of the plasma vertical flows around the SAPS peak latitude are shown. It shows winter over summer preference, resembling the SAPS seasonal variations. 

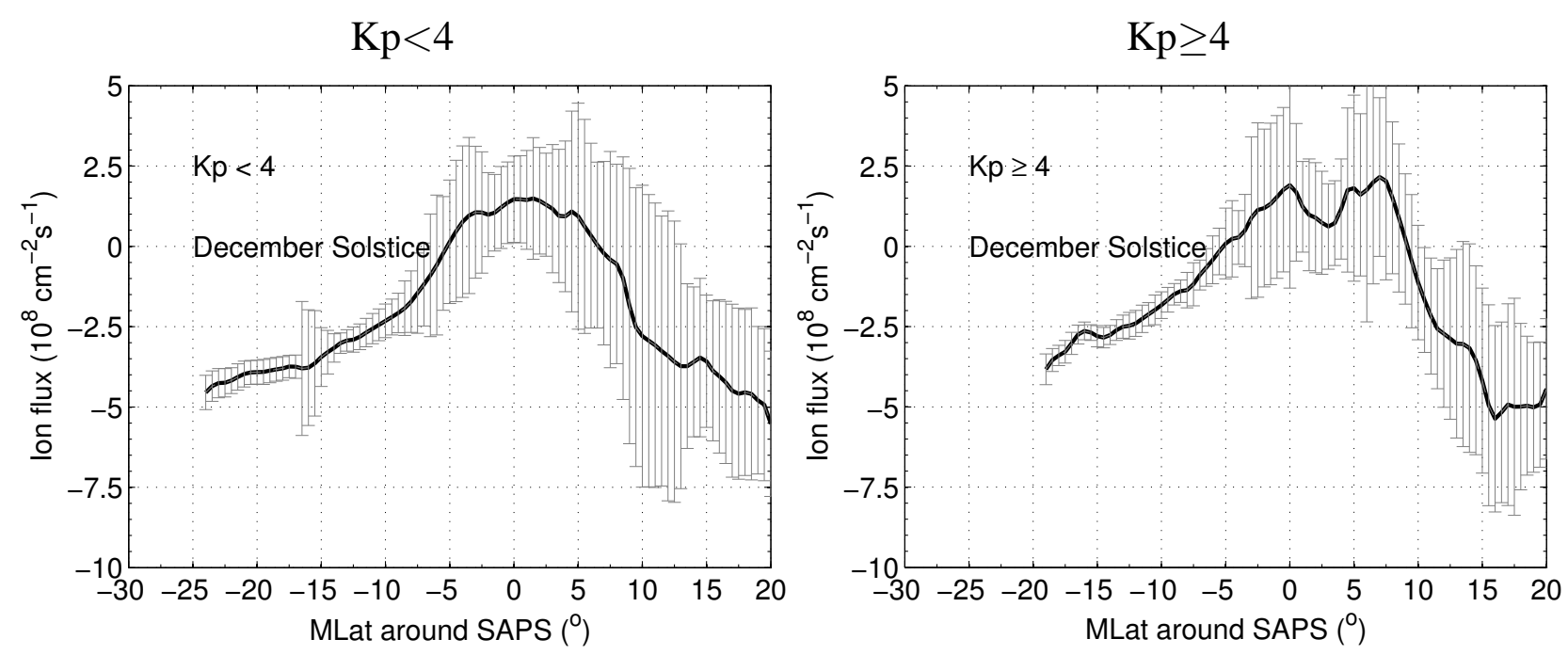

Fig. 9. Superposed epoch analysis of the ion upflow flux in winter for two different Kp levels. The key MLat of " 0 " denotes the latitude where the SAPS velocity peak occurs. Positive denotes upward flux. The bars show the standard deviations of averages.

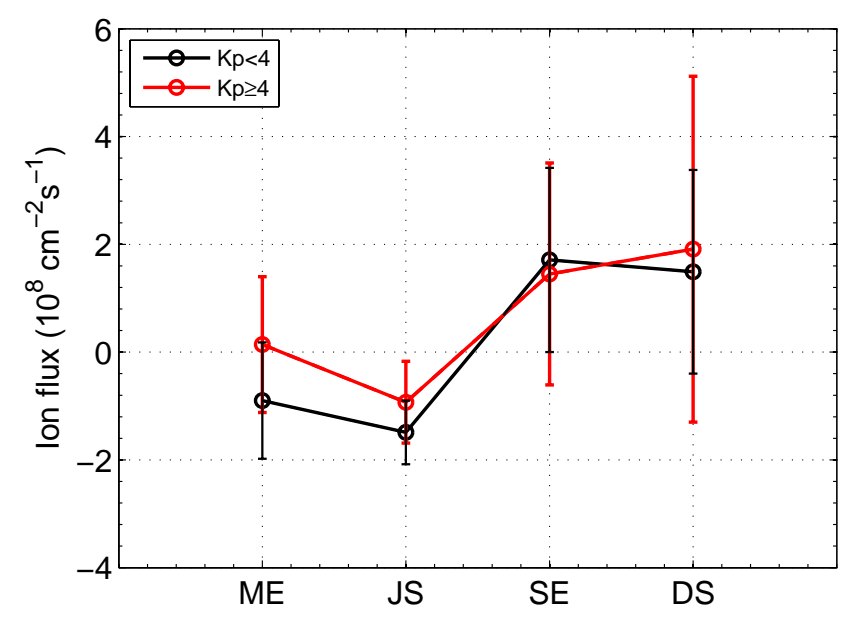

Fig. 10. Seasonal variation of the upflow flux at the key MLat at $800 \mathrm{~km}$ altitude for $\mathrm{Kp}<4$ and $\mathrm{Kp} \geq 4$. The bars show the standard deviations of averages.

In the SAPS region the most important factor that can affect the upflow velocity is the frictional heating caused by ion-neutral collisions. The ion-neutral collision is more effective and faster at lower altitude than at DMSP altitude. It has been found that the frictional heating can affect the temperature most effectively between 400 and $600 \mathrm{~km}$ altitude (Heelis et al., 1993), resulting in a vertical pressure gradient. The altitude gradient of the pressure can cause the plasma expansion and upflow.

In case of frictional heating we can write for the power density, $P_{k}$,

$P_{k}=n_{\mathrm{i}} m_{\mathrm{i}} v_{\mathrm{ni}}(\boldsymbol{v}-\boldsymbol{u}) \cdot \boldsymbol{v}$, where $n_{\mathrm{i}}$ is the ion density, $m_{\mathrm{i}}$ the mean ion mass, $\nu_{\mathrm{ni}}$ the collision frequency between ions and neutrals, $\boldsymbol{v}$ is the plasma velocity vector and $\boldsymbol{u}$ the neutral wind vector. It can be seen that the heating power increases with the square of the plasma velocity at high drift speeds. For that reason it is expected that the SAPS velocity has strong effects on the upflow velocity through affecting the ion temperature primarily between 400 and $500 \mathrm{~km}$ altitude.

The scatter plot of the ion upflow vs. SAPS velocity is shown in Fig. 8. As expected, there is a good correlation between the two parameters, irrespective of the geomagnetic activity. When performing a linear fit it reveals the relation of $V_{z}\left(\mathrm{~m} \mathrm{~s}^{-1}\right)=0.29 \times V_{\text {SAPS }}-170\left(\mathrm{~m} \mathrm{~s}^{-1}\right)$ at DMSP altitude.

Figure 9 shows the latitudinal variation of the upflow flux in winter for example. It can be seen that the average upflow flux can reach about $2 \times 10^{8} \mathrm{~cm}^{-2} \mathrm{~s}^{-1}$ for $\mathrm{Kp} \geq 4$. For completeness, the seasonal variation of the upflow flux in the key MLat where SAPS peak is shown in Fig. 10. It can be seen that the vertical flow velocity and related ion upflow are larger during September equinox and December solstice. The value of upflow flux is within the normal range of the vertical $\mathrm{O}^{+}$flux from $10^{6}$ to $10^{8} \mathrm{~cm}^{-2} \mathrm{~s}^{-1}$ in the dusk sector over a large latitude range $\left(62^{\circ}-78^{\circ}\right.$ ) (Yau et al., 1985); although during intense storms, Yeh and Foster (1990) have reported an extremely large upward flux exceeding $3 \times 10^{9} \mathrm{~cm}^{-2} \mathrm{~s}^{-1}$ in the dusk sector. In the cusp region the typical fluxes of upflow are around $2 \times 10^{8} \mathrm{~cm}^{-2} \mathrm{~s}^{-1}$ at quiet times and $5 \times 10^{8} \mathrm{~cm}^{-2} \mathrm{~s}^{-1}$ at active times $(\mathrm{Kp}=3-5)$ (Yau et al., 1985). Therefore, the subauroral upflow reported here is quite comparable to that in the dayside cusp region. 

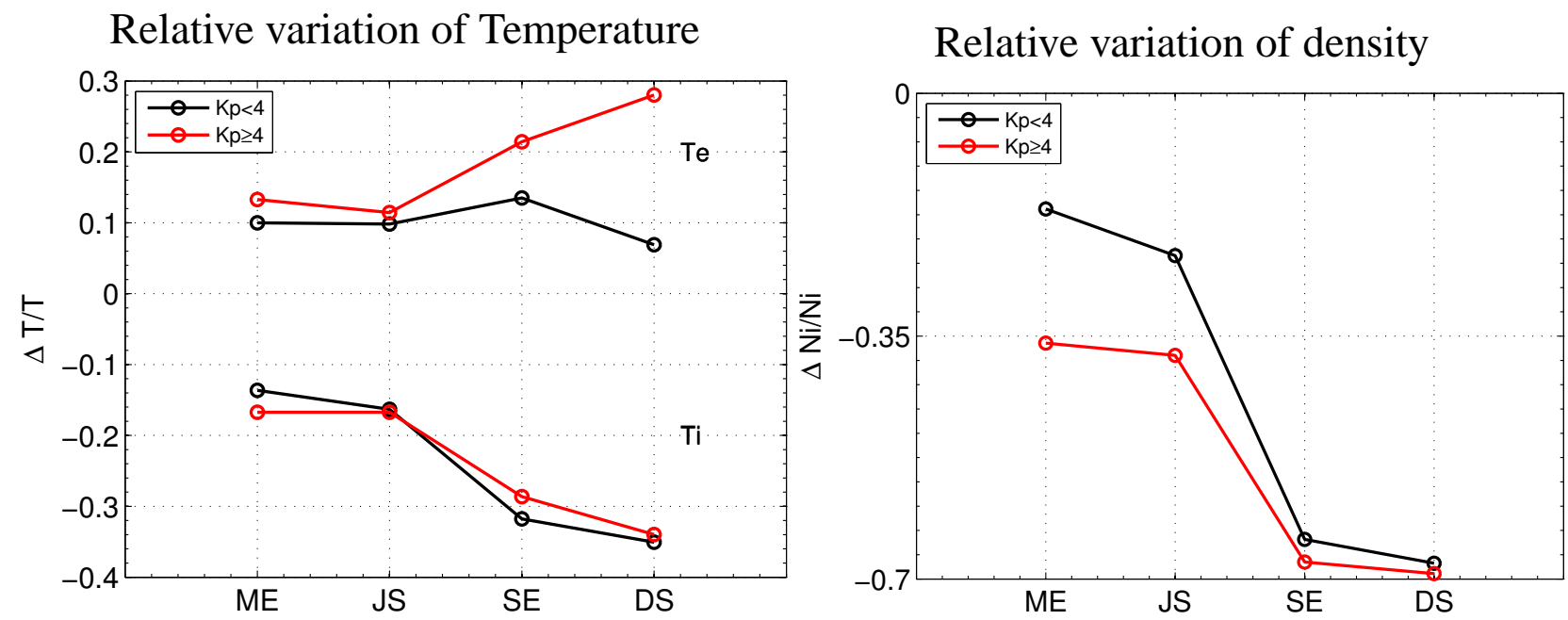

Fig. 11. Relative variation of both ion and electron temperature (left) and ion density (right) at the key MLat at $800 \mathrm{~km}$ altitude for Kp $<4$ and $\mathrm{Kp} \geq 4$ for each season. The $\Delta$ means the subtraction of the background value.

\subsection{Ion and electron temperature}

The study has shown that there is a depression of the ion temperature at $800 \mathrm{~km}$ altitude around the SAPS peak region. The relative changes of the ion temperature with respect to the background trend for each season are depicted in Fig. 11 (left column). The ion temperature has dropped by more than $30 \%$ when compared to the background trend during September equinox and December solstice around the SAPS peak region. The decrease of $T_{\mathrm{i}}$ might be understood in terms of an adiabatic cooling, where $T_{\mathrm{i}}$ is inversely proportional to the specific volume, thus, inversely proportional to the ion concentration. Hanson et al. (1973) have explained the observed ion cooling near the magnetic equator by the adiabatic expansion. They have suggested that the plasma will cool down adiabatically as it expands into regions of decreasing concentrations. When looking at the seasonal variation of the ion density in Fig. 11 (right), it can be seen that ion densities in the topside ionosphere decrease by $70 \%$ during September equinox and December solstice. The increased recombination with electrons and the westward and upward movement during SAPS periods can explain the increase of the trough depth (e.g. Schunk et al., 1976; Anderson et al., 2001).

Figure 11 (left) also shows the seasonal variation of the deviation of the electron temperature with respect to the background trend. The relative deviation of the electron temperature exhibits obvious seasonal variation for more disturbed periods, enhanced by $30 \%$ around the SAPS region during September equinox and December solstice. For less disturbed periods, the relative change of $T_{\mathrm{e}}$ is almost seasonly independent. The main heat source for electrons at midlatitudes is the solar extreme ultraviolet radiation (Schunk and Nagy, 1978). The radiation can produce high-energy photoelectrons, which can heat the ambient electrons by elas- tic collision. The Coulomb collisions with ions are an important energy loss mechanism for the electrons in the topside ionosphere, which are proportional to the ion density (e.g. Schunk and Nagy, 2000; Rother et al., 2010). It is thus expected that the cooling by Coulomb collisions is less effective at lower ion density, which makes the electron temperature higher. Figures 6 and 4 have shown that there are obvious depressions of ion densities in the enhanced $T_{\mathrm{e}}$ region. The seasonal variation of the relatively reduced electron density and the enhanced temperature is almost out of phase for $\mathrm{Kp} \geq 4$ as can be seen from Fig. 11 .

\section{Summary}

In this paper we have studied the effect of SAPS on the ion upflow observed in the topside ionosphere of the Northern Hemisphere by using DMSP observations, which exhibit obvious seasonal variations. Main findings are summarized in the following:

1. In the dusk sector the ion upflow peaks around the same location as the SAPS velocity. The ion upward and westward velocity peaks exhibit similar seasonal variations showing winter over summer preference. Good correlation is found and functional relationships are derived between SAPS and upward velocity. These indicate that the strong SAPS can give increased vertical plasma flow.

2. In winter the average upflow flux can reach about $2 \times$ $10^{8} \mathrm{~cm}^{-2} \mathrm{~s}^{-1}$ for $\mathrm{Kp} \geq 4$. The duskside upflow flux can be comparable to that in the dayside cusp region. 
3. The local ion temperature is depressed around the region where SAPS peak, which can be explained by the adiabatic cooling. The ions convect westward and expand upward during SAPS periods, which further decrease ion concentrations, thus reducing the ion temperature. The local ion temperature decreases around SAPS peaks, which is deeper in winter than in summer.

4. The local electron temperature is somewhat elevated around SAPS regions, which might come from the reduced Coulomb cooling in that region. The local electron temperature increases around SAPS peaks, which is higher in winter than in summer for $K p \geq 4$, but is almost comparable for $\mathrm{Kp}<4$.

The SAPS-related frictional heating at mid-latitudes is essential for the local formation of the strong upward flow, which might provide a direct source of ionospheric ions for the plasmasphere in the dusk sector.

Acknowledgements. We thank the Center for Space Sciences at the University of Texas at Dallas and the US Air Force for providing the DMSP IDM plasma data and the Space Physics Interactive Data Resource (SPIDR) for providing the DMSP SSJ/4 data. The WDC $\mathrm{C} 2$ for Geomagnetism at Kyoto are greatly acknowledged for providing the geomagnetic indices data. This work is supported by the National Nature Science Foundation of China (no. 41222030, 41221003), Program for Young Excellent Scientists by Organization Department, Program for New Century Excellent Talent in University by Ministry of Education.

Topical Editor K. Hosokawa thanks K. Alexandre and two anonymous referees for their help in evaluating this paper.

\section{References}

Anderson, P. C., Heelis, R. A., and Hanson, W. B.: The ionospheric signatures of rapid subauroral ion drifts, J. Geophys. Res., 96, 5785-5792, 1991.

Anderson, P. C., Hanson, W. B., Heelis, R. A., Craven, J. D., Baker, D. N., and Frank, L. A.: A proposed production model of rapid subauroral ion drifts and their relationship to substorm evolution, J. Geophys. Res., 98, 6069-6078, 1993.

Anderson, P. C., Carpenter, D. L., Tsuruda, K., Mukai, T., and Rich, F. J.: Multisatellite observations of rapid subauroral ion drifts (SAID), J. Geophys. Res., 106, 29585-29600, doi:10.1029/2001JA000128, 2001.

Coley, W. R. and Heelis, R. A.: Stormtime measurements of topside ionospheric upflow from Defense Meteorological Satellite Program, J. Geophys. Res., 114, A10305, doi:10.1029/2009JA014350, 2009.

Coley, W. R., Heelis, R. A., and Hairston, M. R.: Characteristics of high-latitude vertical plasma flow from the Defense Meteorological Satellite Program, J. Geophys. Res., 111, A11314, doi:10.1029/2005JA011553, 2006.

Cully, C. M., Donovan, E. F., Yau, A. W., and Arkos, G. G.: Akebono/Suprathermal Mass Spectrometer observations of low-energy ion outflow: Dependence on magnetic activity and solar wind conditions, J. Geophys. Res., 108, 1093, doi:10.1029/2001JA009200, 2003.

Elliott, H. A., Comfort, R. H., Craven, P. D., Chandler, M. O., and Moore, T. E.: Solar wind influence on the oxygen content of ion outflow in the high-altitude polar cap during solar minimum conditions, J. Geophys. Res., 106, 6067-6084, doi:10.1029/2000JA003022, 2001.

Erickson, P. J., Goncharenko, L. P., Nicolls, M. J., Ruohoniemi, M., and Kelley, M. C.: Dynamics of North American sector ionospheric and thermospheric response during the November 2004 superstorm, J. Atmos. Terr. Phys., 72, 292-301, doi:10.1016/j.jastp.2009.04.001, 2010.

Förster, M., Foster, J. C., Smilauer, J., Kudela, K., and Mikhailov, A. V.: Simultaneous measurements from the Millstone Hill radar and the Active satellite during the SAID/SAR arc event of the March 1990 CEDAR storm, Ann. Geophys., 17, 389-404, doi:10.1007/s00585-999-0389-6, 1999.

Foster, J. C. and Burke, W. J.: SAPS: A new categorization for sub-auroral electric fields, EOS Transactions, 83, 393, doi:10.1029/2002EO000289, 2002.

Foster, C. and Lester, M.: Observations of nightside auroral plasma upflows in the F-region and topside ionosphere, Ann. Geophys., 14, 1274-1283, doi:10.1007/s00585-996-1274-1, 1996.

Foster, J. C. and Vo, H. B.: Average characteristics and activity dependence of the subauroral polarization stream, J. Geophys. Res., 107, 1475, doi:10.1029/2002JA009409, 2002.

Galperin, Y., Ponomarev, V. N., and Zosimova, A. G.: Plasma convection in the polar ionosphere, Ann. Geophys., 30, 1-7, 1974.

Ghielmetti, A. G., Johnson, R. G., Sharp, R. D., and Shelley, E. G.: The latitudinal, diurnal, and altitudinal distributions of upward flowing energetic ions of ionospheric origin, Geophys. Res. Lett., 5, 59-62, doi:10.1029/GL005i001p00059, 1978.

Hairston, M. R., Heelis, R. A., and Rich, F. J.: Analysis of the ionospheric cross polar cap potential drop using DMSP data during the National Space Weather Program study period, J. Geophys. Res., 103, 26337-26348, doi:10.1029/97JA03241, 1998.

Hanson, W. B., Nagy, A. F., and Moffett, R. J.: Ogo 6 measurements of supercooled plasma in the equatorial exosphere, J. Geophys. Res., 78, 751-756, doi:10.1029/JA078i004p00751, 1973.

Hardy, D. A., Schmitt, L. K., Gussenhoven, M. S., Marshall, F. J., and Yeh, H. C.: Precipitating electron and ion detectors (SSJ/4) for the block 5D/Flights 6-10 DMSP (Defense Meteorological Satellite Program) satellites: Calibration and data presentation, Rep. AFGL-TR-84-0314, Air Force Geophys. Lab., Air Force Base, MA, 1984.

Heelis, R. A., Winningham, J. D., Sugiura, M., and Maynard, N. C.: Particle acceleration parallel and perpendicular to the magnetic field observed by DE-2, J. Geophys. Res., 89, 3893-3902, doi:10.1029/JA089iA06p03893, 1984.

Heelis, R. A., Bailey, G. J., Sellek, R., Moffett, R. J., and Jenkins, B.: Field-aligned drifts in subauroral ion drift events, J. Geophys. Res., 98, 21493, doi:10.1029/93JA02209, 1993.

Horwitz, J. L. and Moore, T. E.: Four Contemporary Issues Concerning Ionospheric Plasma Flow to the Magnetosphere, Space Sci. Rev., 80, 49-76, doi:10.1023/A:1004973603955, 1997.

Huang, C.-S. and Foster, J. C.: Correlation of the subauroral polarization streams (SAPS) with the Dst index during severe magnetic storms, J. Geophys. Res., 112, 302, 
doi:10.1029/2007JA012584, 2007.

Kervalishvili, G. N. and Lühr, H.: The relationship of thermospheric density anomaly with electron temperature, small-scale FAC, and ion up-flow in the cusp region, as observed by CHAMP and DMSP satellites, Ann. Geophys., 31, 541-554, doi:10.5194/angeo-31-541-2013, 2013.

Korosmezey, A., Rasmussen, C. E., Gombosi, T. I., and Khazanov, G. V.: Anisotropic ion heating and parallel $\mathrm{O}(+)$ acceleration in regions of rapid $\boldsymbol{E} \times \boldsymbol{B}$ convection, Geophys. Res. Lett., 19, 2289-2292, doi:10.1029/92GL02489, 1992.

Lennartsson, O. W., Collin, H. L., and Peterson, W. K.: Solar wind control of Earth's $\mathrm{H}^{+}$and $\mathrm{O}^{+}$outflow rates in the 15 $\mathrm{eV}$ to 33-keV energy range, J. Geophys. Res., 109, A12212, doi:10.1029/2004JA010690, 2004.

Liu, C., Horwitz, J. L., and Richards, P. G.: Effects of frictional ion heating and soft-electron precipitation on highlatitude F-region upflows, Geophys. Res. Lett., 22, 2713-2716, doi:10.1029/95GL02551, 1995.

Liu, H., Ma, S.-Y., and Schlegel, K.: Diurnal, seasonal, and geomagnetic variations of large field-aligned ion upflows in the highlatitude ionospheric F region, J. Geophys. Res., 106, 2465124662, doi:10.1029/2001JA900047, 2001.

Lockwood, M., Waite Jr., J. H., Moore, T. E., Chappell, C. R., and Johnson, J. F. E.: A new source of suprathermal $\mathrm{O}(+)$ ions near the dayside polar cap boundary, J. Geophys. Res., 90, 40994116, doi:10.1029/JA090iA05p04099, 1985.

Loranc, M., St.-Maurice, J.-P., Hanson, W. B., and Heelis, R. A.: A morphological study of vertical ionospheric flows in the high-latitude F region, J. Geophys. Res., 96, 3627-3646, doi:10.1029/90JA02242, 1991.

Malingre, M., Dubouloz, N., Berthelier, J. J., Galperin, Y., Chugunin, D., Perraut, S., Sauvaud, J. A., Delcourt, D., and Stepanov, V.: Low-energy upflowing ion events at the poleward boundary of the nightside auroral oval: High-altitude InterballAuroral probe observations, J. Geophys. Res., 105, 1869318708, doi:10.1029/1999JA000211, 2000.

Moffett, R. J., Sellek, R., and Bailey, G. J.: The behaviour of $\mathrm{H}(+)$ and $\mathrm{He}(+)$ ions in the topside ionosphere during a shortlived subauroral ion drift, 39, 1209-1216, doi:10.1016/00320633(91)90172-7, 1991.

Moffett, R. J., Heelis, R. A., Sellek, R., and Bailey, G. J.: The temporal evolution of the ionospheric signatures of subauroral ion drifts, Planet. Space Sci., 40, 663-670, doi:10.1016/00320633(92)90007-B, 1992.

Moore, T. E., Lundin, R., Alcayde, D., Andre, M., Ganguli, S. B., Temerin, M., and Yau, A.: Source Processes in the High-Latitude Ionosphere, Space Sci. Rev., 88, 7-84, doi:10.1023/A:1005299616446, 1999.

Papadopoulos, K.: A review of anomalous resistivity for the ionosphere, Rev. Geophys., 15, 113-127, doi:10.1029/RG015i001p00113, 1977.

Pollock, C. J., Chandler, M. O., Moore, T. E., Chappell, C. R., and Waite Jr., J. H.: A survey of upwelling ion event characteristics, J. Geophys. Res., 95, 18969-18980, doi:10.1029/JA095iA11p18969, 1990.

Retterer, J. M., Chang, T., and Jasperse, J. R.: Plasma simulation of ion acceleration by lower hybrid waves in the suprauroral region, in: Ion Acceleration in the Magnetosphere and Ionosphere; Proceedings of the AGU Chapman Conference, edited by: Chang,
T., pp. 282-285, 1986.

Rich, F. J. and Hairston, M.: Large-scale convection patterns observed by DMSP, J. Geophys. Res., 99, 3827-3844, 1994.

Robinson, R. M., Vondrak, R. R., Miller, K., Dabbs, T., and Hardy, D. A.: On calculating ionospheric conductances from the flux and energy of precipitating electrons, J. Geophys. Res., 92, 2565-2569, 1987.

Rodger, A. S., Moffett, R. J., and Quegan, S.: The role of ion drift in the formation of ionisation troughs in the mid- and high-latitude ionosphere - A review, J. Atmos. Terr. Phys., 54, 1-30, 1992.

Rother, M., Schlegel, K., Lühr, H., and Cooke, D.: Validation of CHAMP electron temperature measurements by incoherent scatter radar data, Radio Sci., 45, 6020, doi:10.1029/2010RS004445, 2010.

Schunk, R. W. and Nagy, A. F.: Electron temperatures in the F region of the ionosphere - Theory and observations, Rev. Geophys., 16, 355-399, doi:10.1029/RG016i003p00355, 1978.

Schunk, R. W. and Nagy, A.: Ionospheres: Physics, Plasma Physics, and Chemistry, Cambridge University Press, Cambridge, 2000.

Schunk, R. W., Banks, P. M., and Raitt, W. J.: Effects of electric fields and other processes upon the nighttime high-latitude F layer, J. Geophys. Res., 81, 3271-3282, doi:10.1029/JA081i019p03271, 1976.

Sellek, R., Bailey, G. J., Moffett, R. J., Heelis, R. A., and Anderson, P. C.: Effects of large zonal plasma drifts on the subauroral ionosphere, J. Atmos. Terr. Phys., 53, 557-565, 1991.

Sharp, R. D., Johnson, R. G., and Shelley, E. G.: Observation of an ionospheric acceleration mechanism producing energetic/keV/ ions primarily normal to the geomagnetic field direction, J. Geophys. Res., 82, 3324-3328, doi:10.1029/JA082i022p03324, 1977.

Shelley, E. G., Johnson, R. G., and Sharp, R. D.: Satellite observations of energetic heavy ions during a geomagnetic storm, J. Geophys. Res., 77, 6104, doi:10.1029/JA077i031p06104, 1972.

Singh, N., Hwang, K. S., Torr, D. G., and Richards, P.: Temporal features of the outflow of heavy ionospheric ions in response to a high altitude plasma cavity, Geophys. Res. Lett., 16, 29-32, doi:10.1029/GL016i001p00029, 1989.

Southwood, D. J. and Wolf, R. A.: An assessment of the role of precipitation in magnetospheric convection, J. Geophys. Res., 83, 5227-5232, 1978.

Spiro, R. W., Heelis, R. H., and Hanson, W. B.: Rapid sub-auroral ion drifts observed by Atmospheric Explorer C, Geophys. Res. Lett., 6, 657-660, 1979.

Su, Y.-J., Caton, R. G., Horwitz, J. L., and Richards, P. G.: Systematic modeling of soft-electron precipitation effects on highlatitude $\mathrm{F}$ region and topside ionospheric upflows, J. Geophys. Res., 104, 153-164, doi:10.1029/1998JA900068, 1999.

Wahlund, J.-E., Opgenoorth, H. J., Haggstrom, I., Winser, K. J., and Jones, G. O. L.: EISCAT observations of topside ionospheric ion outflows during auroral activity - Revisited, J. Geophys. Res., 97, 3019-3037, doi:10.1029/91JA02438, 1992.

Wang, H., Ridley, A. J., Lühr, H., Liemohn, M. W., and Ma, S. Y.: Statistical study of the subauroral polarization stream: Its dependence on the cross-polar cap potential and subauroral conductance, J. Geophys. Res., 113, 12311, doi:10.1029/2008JA013529, 2008.

Whalen, B. A., Daly, P. W., and Bernstein, W.: Low altitude acceleration of ionospheric ions, Geophys. Res. Lett., 5, 55-58, 
doi:10.1029/GL005i001p00055, 1978.

Wilson, G. R.: Kinetic modeling of $\mathrm{O}(+)$ upflows resulting from $\boldsymbol{E} \times \boldsymbol{B}$ convection heating in the high-latitude $\mathrm{F}$ region ionosphere, J. Geophys. Res., 99, 17453, doi:10.1029/94JA01214, 1994.

Wu, J., Blanc, M., Alcayde, D., Barakat, A. R., Fontanari, J., Blelly, P.-L., and Kofman, W.: Observations of the structure and vertical transport of the polar upper ionosphere with the EISCAT VHF radar. II - First investigations of the topside $\mathrm{O}(+)$ and $\mathrm{H}(+)$ vertical ion flows, Ann. Geophys., 10, 375-393, 1992.

Yau, A. W. and Andre, M.: Sources of Ion Outflow in the High Latitude Ionosphere, Space Sci. Rev., 80, 1-25, doi:10.1023/A:1004947203046, 1997.

Yau, A. W., Whalen, B. A., Peterson, W. K., and Shelley, E. G.: Distribution of upflowing ionospheric ions in the high-altitude polar cap and auroral ionosphere, J. Geophys. Res., 89, 55075522, doi:10.1029/JA089iA07p05507, 1984.
Yau, A. W., Lenchyshyn, L., Shelley, E. G., and Peterson, W. K.: Energetic auroral and polar ion outflow at DE 1 altitudes Magnitude, composition, magnetic activity dependence, and long-term variations, J. Geophys. Res., 90, 8417-8432, doi:10.1029/JA090iA09p08417, 1985.

Yeh, H.-C. and Foster, J. C.: Storm time heavy ion outflow at mid-latitude, J. Geophys. Res., 95, 7881-7891, doi:10.1029/JA095iA06p07881, 1990.

Yeh, H.-C., Foster, J. C., Rich, F. J., and Swider, W.: Storm time electric field penetration observed at mid-latitude, J. Geophys. Res., 96, 5707-5721, 1991. 